\title{
ANALYSIS OF GLOBAL URBAN TEMPERATURE TRENDS AND URBANIZATION IMPACTS
}

\author{
Kyung Il Lee ${ }^{1}$, Jieun Ryu², Seong Woo Jeon ${ }^{1 *}$ \\ ${ }^{1}$ Environmental Science \& Ecological Engineering, Korea University, 145 Anam-ro, Seongbuk-gu, Seoul, KOREA - \\ leedake@kroea.ac.kr, eepps_korea@korea.ac.kr \\ ${ }^{2}$ Environmental GIS/RS Center, Korea University, 145 Anam-ro, Seongbuk-gu, Seoul, KOREA - ulygajok@gmail.com
}

Commission III, WG III/7

KEY WORDS: Urbanization, Climate change, Global Warming, Surface temperature, GLDAS-2, MODIS,

\begin{abstract}
:
Due to urbanization, urban areas are shrinking green spaces and increasing concrete, asphalt pavement. So urban climates are different from non-urban areas. In addition, long-term macroscopic studies of urban climate change are becoming more important as global urbanization affects global warming. To do this, it is necessary to analyze the effect of urbanization on the temporal change in urban temperature with the same temperature data and standards for urban areas around the world.

In this study, time series analysis was performed with the maximum, minimum, mean and standard values of surface temperature during the from 1980 to 2010 and analyzed the effect of urbanization through linear regression analysis with variables (population, night light, NDVI, urban area).

As a result, the minimum value of the surface temperature of the urban area reflects an increase by a rate of $0.28 \mathrm{~K}$ decade ${ }^{-1}$ over the past 31 years, the maximum value reflects an increase by a rate of $0.372 \mathrm{~K}$ decade ${ }^{-1}$, the mean value reflects an increase by a rate of 0.208 decade $^{-1}$, and the standard deviation reflects a decrease by rate of $0.023 \mathrm{~K} \mathrm{decade}^{-1}$. And the change of surface temperature in urban areas is affected by urbanization related to land cover such as decrease of greenery and increase of pavement area, but socioeconomic variables are less influential than NDVI in this study.

This study are expected to provide an approach to future research and policy-planning for urban temperature change and urbanization impacts.
\end{abstract}

\section{INTRODUCTION}

Due to urbanization, urban areas are shrinking green spaces, increasing concrete, asphalt pavement and buildings. As a result, urban climates are different from non-urban areas, and many studies have been carried out to identify climate change due to urbanization, causing problems such as changes in precipitation, elevation of surface temperature, and urban heat island phenomenon (Douglas, 1981; Oke, 1982; Karl et al., 1988; Stoll and Brazel, 1992; Clinton and Gong, 2013).

Studies related to urban climate have been mostly based on microscopic studies to identify and analyze the causes of ground surface temperature depending on features such as land cover and building density in cities. However, as some research results have been published stating that global urbanization affects global warming together with greenhouse gases, the importance of macroscopic urban climate studies is increasing (Karl et al., 1988; Jones et al., 1990; Pielke, 2005; Yang et al., 2011; Clinton and Gong, 2013). However, the existing macroscopic urban climate change researches are based on the characteristics of different regions and cities due to the difficulty of quantitative and comparative analysis applying the same data and standards to the urban regions of the world. Instead, they have consisted of case studies focusing on the national and regional areas, where it is easier to acquire observational data rather than data for temperature changes (Karl et al., 1988; Jones et al., 1990; Hua et al., 2008; yang et al., 2011).
Karl et al. (1988) classified urbanization by population and analyzed the minimum temperature, the mean temperature, and the temperature range with monthly temperature data from 1,219 stations of the Historical Climatology Network (HCN) from 1901 to 1984. As a result, it was found that as the degree of urbanization increases, the minimum and average temperatures increase while the temperature range tends to decrease, most visible in summer and autumn respectively. Jones et al. (1990) conducted an inverse-distance weighting spatial interpolation technique using the regional temperature data for each region in Western Soviet Union, Eastern Australia, and Eastern China, but found that there was no significant effect except the Eastern China region. However, it can be concluded that there is no accurate comparative analysis on the three regions due to the irregularities in factors such as the temperature data used in each region, the timing of analysis, and the number of grids for deriving the average temperature. The results of this study also showed the necessity of analyzing the effect of urbanization on unified temperature data and timing throughout the world. In a study of Hua et al (2008) in China, cities were selected and categorized by population, and 282 meteorological stations were used to estimate the difference in atmospheric temperature between cities. Time series analysis was performed for maximum, minimum, average, and temperature ranges. As a result of the analysis, large cities showed a tendency to increase by about $0.05{ }^{\circ} \mathrm{C}$ every 10 years and $0.03{ }^{\circ} \mathrm{C}$ in medium and small cities from 1980 when the

\footnotetext{
* Corresponding author
} 
rapid development of China started. In the study of east China of Yang et al. (2011), nighttime light images were used to classify the degree of urban development, and monthly mean surface air temperature data of 463 meteorological stations were used to estimate the temperature from 1981 to 2007 time series change. As a result of the analysis, it was found that the temperature increases every decade as the degree of urban development increases. The temperature difference between urban and non - urban areas appears to be best in summer.

Based on the existing research results, it can be concluded that most of the study areas were the countries and regions where the meteorological data were well constructed, and there were differences in the urbanization standards and the analysis periods for each study. In addition, there were incompleteness and non-uniformity of time series analysis due to different meteorological data. Therefore, it seems insufficient to confirm the trend of urban temperature and the effect of urbanization in the world. While there may be differences in the form of urbanization by country depending on policy and environment, the overall tendency of population growth and land cover change is similar. Therefore, it is necessary to identify trends in the time series of temperature changes in urban areas around the world with the same data and standards and analyze the effect of urbanization on them.

Therefore, the purpose of this study is to confirm the change of temperature in urban area around the world using the same temperature data and to confirm the effect of urbanization on it. Based on the results of previous research that the increase in surface temperature due to urbanization is the largest in summer, time series analysis was performed with the maximum, minimum, mean and standard values of surface temperature during the summer from 1980 to 2010. In addition, the effect of urbanization was examined through linear regression analysis with variables related to urbanization (population, night light, NDVI, urban area).

\section{MATERIALS AND ANALYSIS METHOD}

\subsection{Materials}

In this study, MCD12C1, a land cover image provided by Moderate Resolution Imaging Spectroradiometer (MODIS) was used for the extraction of corresponding point data in the urban area between 71 and -51 degrees latitude. The MCD12C1 is an image that provides global land cover through modeling using MODIS Terra and Aqua sensor data at $0.05^{\circ}(\sim 5600 \mathrm{~m})$ resolution (Friedl et al., 2002).

For the surface temperature extraction, the Global Land Data Assimilation System Version 2 (GLDAS-2, Noah model) provided by National Aeronautics and Space Administration (NASA) was used. GLDAS-2 is a spatial image of global surface information at $1.0^{\circ}$ and $0.25^{\circ}$ resolution between 1948 and 2010 using satellite image, ground observation data, and NOAH Land surface model (Rodell et al., 2004).

Nighttime light imagery was obtained from Defense Meteorological Satellite Program Operational Linescan System(DMSP-OLS) from National Oceanic And Atmospheric Administration(NOAA). Nighttime light is used as an index of development intensity many studies (Elvidge et al., 2009; Small et al., 2005). The DMSP/OLS image shows lights from cities, towns, and other sites with persistent lighting and has digital number values ranging from 0 to 63 . Areas with zero cloud-free observations are represented by the value 255 (Yang et al., 2011).

Population data were constructed using Gridded Population of the World, Version 4 (GPWv4) provided by NASA Socioeconomic Data and Applications Centers (SEDAC). GPWv4 is a gridded data product of globally-integrated national population data from the 2010 round of Population and Housing Censuses. The gridded data sets are constructed from national or subnational input administrative units. GPWv4 is gridded with an output resolution of 30 arc-seconds at equator (CIESIN, 2016).

MOD13 products, which are provided by MODIS, were used to confirm the degree of greening of urban areas. MOD13 products provide consistent spatial and temporal time series comparisons of global vegetation conditions. In this paper, a new model of the clustering model (CMG) (Didan et al., 2015) was proposed. Using this image, the Normalized Difference Vegetation Index (NDVI) of each urban area was extracted. NDVI is unitless in $[-0.2,1.0]$ with higher values indicating higher greenness (Clinton and Gong, 2013).

\subsection{Analysis Method}

In this study, the time series change of the surface temperature of the summer (June, July, and August) of the global urban area from 1980 to 2010 was analyzed. Based on the assumption that the global urbanization level is the highest in 2010, a linear regression analysis was conducted using temperature and urbanization related variables to examine the effect of urbanization on urban surface temperature.

The land cover image of MCD12C1 2010 was used to extract the location point of the urban area between latitude 71 degrees and -55 degrees. The MCD12C1 image divides the land cover of water, grasslands, croplands, etc. into 17 classification types, identifies urban and built-up area using ArcGIS 10.4 tools and extracts the location points of urban area.

The surface temperature in summer is defined as the mean value of surface temperature in June, July, and August of each year with reference to Yang et al., (2011). From the 1980s to the year 2010, the summer surface temperature was calculated for each year, and the summer surface temperature of each urban area was derived using the extracted location points of urban areas. The maximum, minimum, average, and the standard deviation were calculated and analyzed by time series to confirm the tendency of the surface temperature change in the urban area. The SPSS 24 program was used for descriptive statistics, and the outlier points extracted out of the image range were excluded from the analysis. 


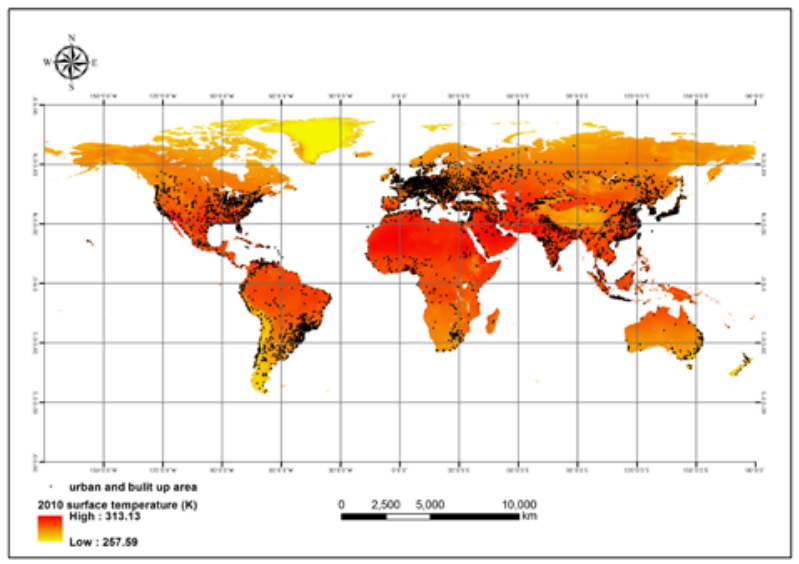

Figure 1. Urban surface temperature and urban area location point

In order to construct the variables, the urban area was constructed by calculating the area (in square kilometers) of each urban and built-up area using the MCD12C1 land cover image. In order to construct the NDVI variables, the mean value of MOD13C2 images (June, July, and August in 2010) was calculated. The nighttime light and population data are constructed on a yearly basis. The parameters for the linear regression analysis were extracted using the urban area location points and the outlier points extracted outside the image value range were excluded before analysis.

Linear regression analysis generally assumes a linear relationship between dependent variables and independent variables. However, the dependent variable of this study, the surface temperature, does not have a perfectly linear relationship with the independent variables - nighttime light, NDVI, population, and urban area. The relationship is rather nonlinear with a horizontal effect. In order to make the relationship between the dependent and independent variables linear in this study, the Pearson correlation between the value of the original form, the square root form or the log form and the surface temperature of each variable was conducted with reference to the study of Lee et al. (2007). Based on the correlation coefficients and significance probabilities extracted from the correlation analysis, the most suitable form was selected for linear regression analysis of each variable.

Linear regression analysis was performed using the selected variables and the effect of each variable on the surface temperature of the urban area was confirmed.

\begin{tabular}{|c|c|c|}
\hline Variable & Description(unit) & Source \\
\hline $\begin{array}{l}\text { Surface } \\
\text { temperature }\end{array}$ & $\begin{array}{c}\text { Average of June, } \\
\text { July, August Surface } \\
\text { Skin temperature(K) }\end{array}$ & $\begin{array}{l}\text { Naional AeronatiticsandSpace } \\
\text { Administation(NASA) }\end{array}$ \\
\hline Greenness & $\begin{array}{l}\text { Average of June, } \\
\text { July, August Nomalized } \\
\text { DifferenceVegeationIndex(unit } \\
\text { less) }\end{array}$ & $\begin{array}{l}\text { ModeateResolutionImaging } \\
\text { Spectroradiomete(MODIS) }\end{array}$ \\
\hline Urban area & $\begin{array}{c}\text { unbanandbuiltupareasize } \\
\text { whereeadhuibanarealocation } \\
\text { pointisextraded(km²) }\end{array}$ & $\begin{array}{l}\text { ModeateResolutionImaging } \\
\text { Spectoriadiamete(MODIS) }\end{array}$ \\
\hline
\end{tabular}

$\begin{array}{ccc} & \text { averageof2010visibleband } & \\ \text { Nighttime } & \text { digitalnumberofdoudffieelight } & \text { NaionalOceanicAnd } \\ \text { light } & \text { detectionsmultipliedbythe } & \text { Amoospheic } \\ & \text { percentffiequency oflight } & \text { Administation(NOAA) } \\ & \text { detection(unitless) } & \end{array}$

Population

globally-integratednational

NASASocioeconomic Data populationdata(number)
Table 1. Variables for Linear regression analysis

\section{RESULTS}

\subsection{Urban area Surface temperature Trend}

A total of 5,775 points were extracted from the latitude between 71 and -55 urban area points of the MCD12C1 land cover image. The extracted points were used to draw the values of surface temperature of the urban area in summer, and the outlier was removed. As a result, 5,379 urban area points for each year were used for descriptive statistical analysis.

The minimum, maximum, average, and standard deviation for each year were calculated by descriptive statistical analysis using 5,379 urban point surface temperature data and analyzed by time series. As a result of the time-series analysis, the minimum value of the surface temperature of the urban area reflects an increase by a rate of $0.28 \mathrm{~K}$ decade- 1 over 31 years, the maximum value reflects an increase by a rate of $0.372 \mathrm{~K}$ decade- 1 , the mean value reflects an increase by a rate of 0.208 decade- 1 , and The standard deviation reflects a decrease by rate of $0.023 \mathrm{~K}$ decade- 1 .

Karl and Jones (1989) studied the US during the 1901-84 period and concluded that the urbanization in the American annual mean Surface Air Temperature (SAT) series is $+0.1^{\circ} \mathrm{C}$ to $+0.4^{\circ} \mathrm{C}$, which is almost equivalent to the overall climate warming trend $\left(+0.16^{\circ} \mathrm{C}\right)$ in the same time period. In the study of Zhou et al. (2004), which measured temperature changes in China using surface data, it was concluded that the rate of temperature warming brought about by urbanization in southeast China was $0.05{ }^{\circ} \mathrm{C}$ decade-1. Compared to the previous studies, the results of this study show that the increase in degree of the minimum, the maximum, and the average temperature in overall urban areas are higher. In addition, Karl et al. (1988) showed that in the US from 1901 to 1984, the maximum temperature change due to urbanization tended to decrease, while the present study showed an increasing trend. In addition, the standard deviation of temperature in urban areas due to urbanization tends to decrease, suggesting that the global urbanization reduces the temperature variation in urban areas around the world.

The results of this analysis show that compared with the tendency of existing urbanization which was mainly made up of developed countries such as the US and Europe, the higher temperature increase tendency is made due to the globalization of urbanization including the urbanization of the Asian countries centering on the Chinese revolution around 1980 and the urbanization of the African countries including the countries with more population than the existing developed countries (Song, 2014). 
The results of the descriptive analysis are summarized in Table 2. The time series analysis results for minimum, maximum, average and standard deviation are summarized in Fig.2, Fig.3 and Fig.4.

\begin{tabular}{|c|c|c|c|c|c|}
\hline Year & $\operatorname{Min}(\mathbf{K})$ & $\operatorname{Max}(K)$ & Mean(K) & SD(K) & $\mathbf{N}$ \\
\hline 1980 & 272.786 & 312.043 & 294.915 & 6.124 & 5,379 \\
\hline 1981 & 273.628 & 312.105 & 295.175 & 6.051 & 5,379 \\
\hline 1982 & 271.334 & 311.709 & 295.216 & 5.794 & 5,379 \\
\hline 1983 & 273.771 & 312.101 & 295.509 & 5.976 & 5,379 \\
\hline 1984 & 271.402 & 311.971 & 294.973 & 6.190 & 5,379 \\
\hline 1985 & 274.095 & 311.849 & 294.969 & 6.047 & 5,379 \\
\hline 1986 & 273.513 & 312.428 & 295.205 & 5.963 & 5,379 \\
\hline 1987 & 272.997 & 312.705 & 295.184 & 6.213 & 5,379 \\
\hline 1988 & 273.771 & 313.301 & 295.453 & 6.083 & 5,379 \\
\hline 1989 & 273.739 & 312.608 & 295.253 & 5.843 & 5,379 \\
\hline 1990 & 273.641 & 312.184 & 295.331 & 6.030 & 5,379 \\
\hline 1991 & 272.631 & 311.679 & 295.402 & 5.899 & 5,379 \\
\hline 1992 & 272.749 & 312.003 & 295.170 & 5.776 & 5,379 \\
\hline 1993 & 273.749 & 312.583 & 294.970 & 6.090 & 5,379 \\
\hline 1994 & 273.030 & & 295.709 & 5.878 & 5,379 \\
\hline 1995 & 271.620 & 312.818 & 295.742 & 5.888 & 5,379 \\
\hline 1996 & 274.233 & 312.767 & 2 & 6.088 & 5,379 \\
\hline 1997 & 273.079 & 312.615 & 295.447 & 5.830 & 5,379 \\
\hline 1998 & 275.320 & 313.729 & & 6.130 & 5,379 \\
\hline 1999 & 273.697 & 313.112 & 295.642 & 5.924 & 5,379 \\
\hline 2000 & 272.696 & 313.099 & 295. & 6.129 & 5,379 \\
\hline 2001 & 273.232 & 312.740 & 295.668 & 5.887 & 5,379 \\
\hline 2002 & 272.720 & 313.112 & 295.769 & 5.944 & 5,379 \\
\hline 2003 & 274.280 & 313.222 & 295.876 & 5.789 & 5,379 \\
\hline 2004 & 274.443 & 312.219 & 295.268 & 5.881 & 5,379 \\
\hline 2005 & 273.204 & 313.083 & 295.693 & 5.970 & 5,379 \\
\hline 2006 & 273.843 & 313.775 & 295.978 & 5.848 & 5,379 \\
\hline 2007 & 273.822 & 313.409 & 295.758 & 6.166 & 5,379 \\
\hline 2008 & 273.359 & 312.574 & 295.686 & 5.914 & 5,379 \\
\hline 2009 & 273.821 & 312.967 & 295.609 & 6.093 & 5,379 \\
\hline 2010 & 273.263 & 312.270 & 295.163 & 5.981 & 5,379 \\
\hline
\end{tabular}

Table 2. Descriptive statistics results of summer surface temperature anomalies in latitude [71,-51] urban areas during 1980-2010.

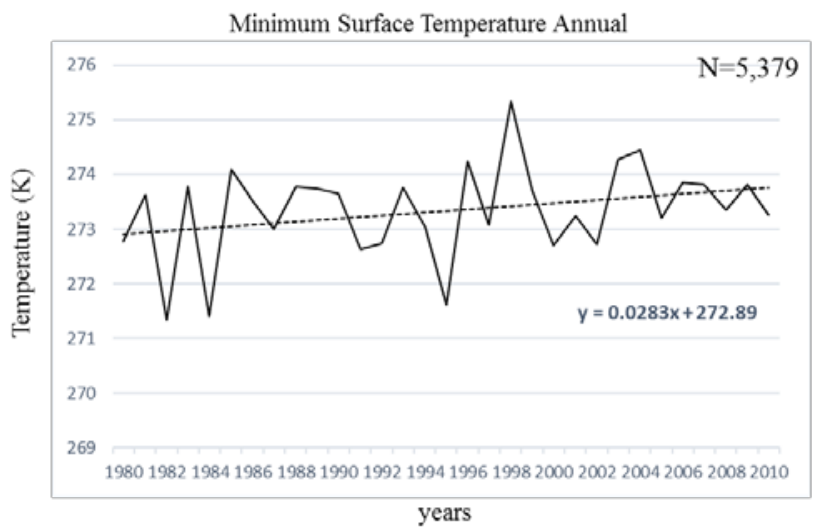

Figure 2. Time series of the minimum summer surface temperature anomalies in latitude [71,-51] urban areas during 1980-2010.

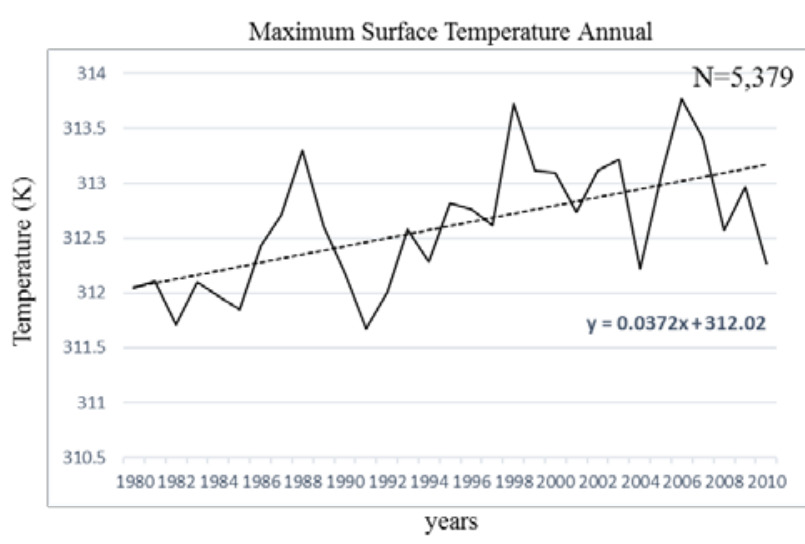

Figure 3. Time series of the maximum summer surface temperature anomalies in latitude [71,-51] urban areas during 1980-2010.

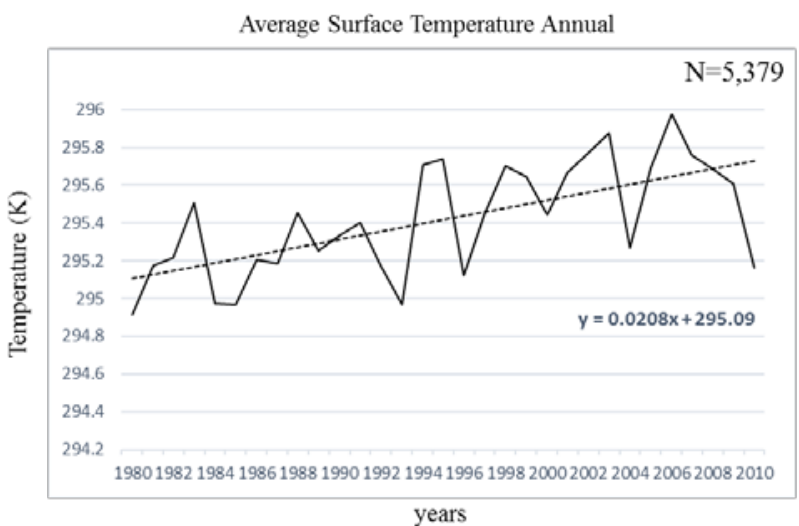

Figure 4. Time series of the average summer surface temperature anomalies in latitude [71,-51] urban areas during 1980-2010. 


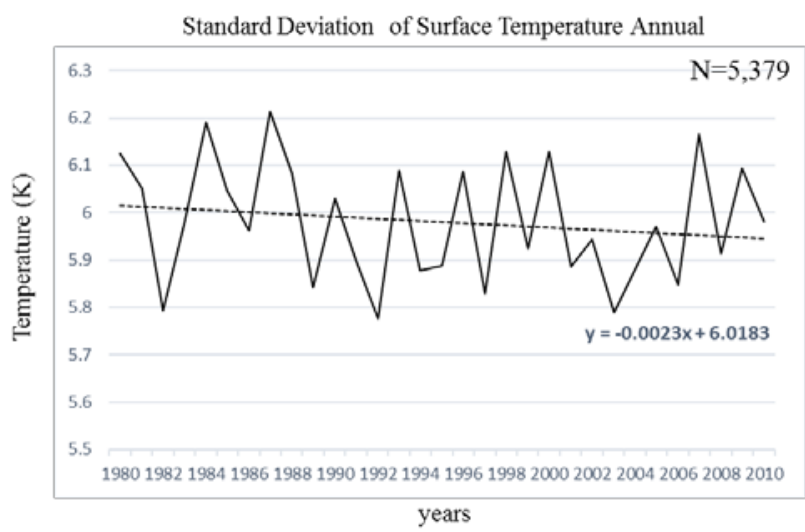

Figure 5. Time series of the standard deviation of summer surface temperature anomalies in latitude [71,-51] urban areas during 1980-2010.

\subsection{Linear regression analysis}

The Pearson correlation analysis was used to select the most suitable form for each variable. As the highest correlation coefficient, the correlation coefficient of nighttime light was found to be 0.183 , and the correlation coefficient of root form NDVI was -0.311 . The log form population has a correlation coefficient of 0.185 and the log form urban area has a correlation coefficient of 0.165 . Each type of variable was used for linear regression analysis. The correlation analysis results are summarized in Table 3.

\begin{tabular}{|c|c|c|}
\hline Variables & $\begin{array}{c}\text { Correlation } \\
\text { coefficient }(r)\end{array}$ & $\mathrm{N}$ \\
\hline nighttime light & $0.183^{* * *}$ & 5368 \\
\hline $\begin{array}{c}\log _{10} \\
\text { (nighttime light) }\end{array}$ & $0.120^{* *}$ & 5359 \\
\hline $\begin{array}{c}\text { Root } \\
\text { (nighttime light) }\end{array}$ & $0.165^{* *}$ & 5368 \\
\hline NDVI & $-0.310^{* *}$ & 5368 \\
\hline $\log _{10}(\mathrm{NDVI})$ & $-0.308^{* *}$ & 5366 \\
\hline Root(NDVI) & $-0.311^{* * *}$ & 5366 \\
\hline population & $0.152^{* *}$ & 5368 \\
\hline $\log _{10}$ (population) & $0.185^{* * *}$ & 5350 \\
\hline Root(population) & $0.166^{* *}$ & 5368 \\
\hline urban area & $0.074^{* *}$ & 5368 \\
\hline $\log _{10}($ urban area) & $0.165^{* * *}$ & 5368 \\
\hline Root(urban area) & $0.122^{* *}$ & 5368 \\
\hline
\end{tabular}

$* * \mathrm{p}<0.01$
Table 3. Pearson correlation analysis results of each variable. The highest correlation index for each variable is outlined.

The linear regression analysis using the selected variables showed that the p-value was less than 0.01 . The p-value for each variable was 0.036 for nighttime light, and NDVI, population, and urban area were less than 0.01 . Therefore, it can be concluded that there is a significant effect on temperature.

NDVI was the most influential variable for the surface temperature of urban area based on the standardized coefficient (Beta). In this study, the NDVI is a variable related to the urban land cover, which is analyzed as a significant influence in the study of the urban temperature change (Lee et al., 2017; Tayyebi et al., 2018). Among the variables other than NDVI, the most influential variable was population. In the case of population, it is used as an indicator of degree of urbanization in existing research and policy making (Karl et al., 1988; Clinton and Gong, 2013; Song, 2014). As a socioeconomic indicator rather than a land cover variable, the population is considered to be an appropriate variable for analysis of urban temperature change and prediction. In the case of nighttime light and urban area, the urban area has a higher influence. However, compared to the NDVI and the population, the two variables have relatively little influence on urban temperature. The results of the linear regression analysis are summarized in Table 4.

\begin{tabular}{c|c|c|c|c}
\hline & $\begin{array}{c}\text { nighttime } \\
\text { light }\end{array}$ & NDVI & population & $\begin{array}{c}\text { urban } \\
\text { area }\end{array}$ \\
\hline B & 0.12 & -14.831 & 1.092 & 0.889 \\
Std. & 0.006 & 0.684 & 0.101 & 0.218 \\
Error & & & & \\
Std B & 0.030 & -0.293 & 0.151 & 0.056 \\
T & 2.095 & -21.679 & 10.763 & 4.085 \\
& & & & \\
P-value & 0.036 & $\mathrm{p}<0.01$ & $\mathrm{p}<0.01$ & $\mathrm{p}<0.01$ \\
\hline
\end{tabular}

${ }^{\mathrm{a}} \mathrm{R}=0.366, \mathrm{R}^{2}=0.134$, Adjusted $\mathrm{R}^{2}=0.133 \mathrm{~W}, \mathrm{~F}=206.065, \mathrm{P}<0.01$

Table 4. Linear regression analysis result between urban area surface temperature and nighttime light, NDVI, population, urban area in summer 2010

\section{CONCLUSION AND DISCUSSION}

In this study, the time-series analysis of the surface temperature of summer months of June, July, and August from 1980 to 2010 were analyzed for latitude between 71 and 55 urban areas, and the effect of urbanization on urban surface temperature was examined by linear regression analysis using urban surface temperature and urbanization variables in 2010. As a result of the time-series analysis, the minimum value of the surface temperature of the urban area reflects an increase by a rate of $0.28 \mathrm{~K}$ decade $^{-1}$ over the past 31 years, the maximum value reflects an increase by a rate of $0.372 \mathrm{~K}_{\text {decade }}{ }^{-1}$, the mean value reflects an increase by a rate of 0.208 decade $^{-1}$, and The 
standard deviation reflects a decrease by rate of $0.023 \mathrm{~K}$ decade 1 .

The results indicate that compared with the tendency of existing urbanization which was mainly made up of developed countries such as the US and Europe, the higher temperature increase tendency is caused due to the globalization of urbanization including the urbanization of the Asian countries centering on the Chinese revolution around 1980 and the urbanization of the African countries including the countries with more population than the existing developed countries. Linear regression analysis result showed that NDVI, which is directly related to the land cover, has the greatest effect on urban surface temperature. In the cases of non-land cover variables, the population was the most influential while the urban area and nighttime light had a relatively small impact. Therefore, the change of surface temperature in urban areas around the world is affected by urbanization related to land cover such as decrease of greenery and increase of pavement area, but socioeconomic variables are less influential in urban area surface temperature change and prediction analysis.

It is significant that this study used the uniform temperature data and criteria to analyze the changes in surface temperature for urban areas around the world and to confirm the effect of urbanization. However, since the materials of this study are constructed through modeling, there are limitations in the analysis caused by differences in the measurement data, model program, standard, and spatial scale used during modeling process. There are also limitations in not analyzing more urban temperature trends and not using more urbanization related variables. In the future, it will be possible to predict and investigate the temperature change in the urban area more accurately by examining the change trend using the higher resolution image and analyzing the cause considering more urbanization related variables.

\section{ACKNOWLEDGEMENTS}

This study was carried out with the support of Korea Meteorological Administration as part of Research \& Development Program with a See-At (See+Atmosphere) grant (KMIPA 2015-6140).

\section{REFERENCES}

Center for International Earth Science Information Network CIESIN - Columbia University. 2016. Documentation for the Gridded Population of the World, Version 4 (GPWv4). Palisades NY: NASA Socioeconomic Data and Applications Center (SEDAC). http://dx.doi.org/10.7927/H4D50JX4 1202 2018.

Clinton, N., and Gong, P., 2013. MODIS detected surface urban heat islands and sinks: Global locations and controls. Remote Sensing of Environment, 134, pp. 294-304.

Douglas, I., 1981. The city as an ecosystem. Progress in Physical Geography, 5(3), pp. 315-367.

Du, Y., Z. Xie, Y. Zeng, Y. Shi, and J. Wu., 2007. Impact of urban expansion on regional temperature change in the Yangtze River Delta, J. Geogr. Sci., 17(4), pp. 387 - 398, doi:10.1007/s11442-007-0387-0.
Elvidge, C. D., Sutton, P. C., Tuttle, B. T., Ghosh, T., and Baugh, K. E., 2009. Global urban mapping based on nighttime lights. In P. Gamba, \& M. Herold (Eds.), Global Mapping of human settlement: Experiences, data sets and prospects.: CRC Press.

Friedl, M. A., McIver, D. K., Hodges, J. C., Zhang, X. Y., Muchoney, D., Strahler, A. H., ... and Baccini, A., 2002. Global land cover mapping from MODIS: algorithms and early results. Remote Sensing of Environment, 83(1-2), pp. 287-302.

Gong, D. Y., and S. W. Wang., 2002. Uncertainties in the global warming studies [in Chinese], Earth Sci. Front., 9(2), pp. 371376.

Heisler, G. M., \& Brazel, A. J., 2010. The urban physical environment: Temperature and urban heat islands. Urban ecosystem ecology, (urbanecosysteme), pp. 29-56.

Hua, L. J., Ma, Z. G., \& Guo, W. D., 2008. The impact of urbanization on air temperature across China. Theoretical and Applied Climatology, 93(3-4), pp. 179-194.

Jones, P. D., Groisman, P. Y., Coughlan, M., Plummer, N., Wang, W. C., \& Karl, T. R. 1990. Assessment of urbanization effects in time series of surface air temperature over land. Nature, 347(6289), 169.

Karl, T. R., Diaz, H. F., \& Kukla, G., 1988. Urbanization: Its detection and effect in the United States climate record. Journal of climate, 1(11), pp. 1099-1123.

Karl, T. R., \& Jones, P. D., 1989. Urban bias in area-averaged surface air temperature trends. Bulletin of the American Meteorological Society, 70(3), pp. 265-270.

Lee, K.,I., Ryu., J., E., Jeon., S., W., Jung., H.,C., and Kang., J., Y., 2017. Analysis of the Effect of Heat Island on the Administrative District Unit in Seoul Using LANDSAT Image., Korean Journal of Remote Sensing, 33(5-3), pp. 821-834.

Lee, S. Y., Lee, J.H., and Hwang, M.,J., 2007. A Study of the Transformation of the dependent variable in non-linear regression.

NASA Goddard Earth Sciences Data and Information Services Center(GES DISC), 2016, Global Land Data Assimilation System Version 2 (GLDAS-2) Products, accessed February 10, 2018, at http://hydro1.gesdisc.eosdis.nasa.gov/data/GLDAS/.

Oke, T. R., 1982. The energetic basis of the urban heat island. Quarterly Journal of the Royal Meteorological Society, 108(455), pp. 1-24.

Pielke, R. A., 2005. Land use and climate change. Science, 310(5754), pp. 1625-1626.

Rodell, M., P. R. Houser, U. Jambor, J. Gottschalck, K. Mitchell, C.-J. Meng, K. Arsenault, A. Cosgrove, J. Radakovich, M. Bosilovich, J. K. Entin, J. P. Walker, D. Lohmann, and D. Toll., 2004. The Global Land Data Assimilation System, Bull. Amer. Meteor. Soc., 85(3), pp. 381-394.

Small, C., Pozzi, F., \& Elvidge, C., 2005. Spatial analysis of 
global urban extent from DMSP-OLS night lights. Remote Sensing of Environment, 96(3-4), pp. 277-291.

Solano, R., Didan, K., Jacobson, A., \& Huete, A., 2010. MODIS vegetation index user's guide (MOD13 series). Vegetation Index and Phenology Lab, The University of Arizona, 1-38.

Song, M.,K., 2014, Core issues of global urbanization and prospects for growth in emerging cities, The Seoul Institute.

Stoll, M. J., \& Brazel, A. J., 1992. Surface-air temperature relationships in the urban environment of Phoenix, Arizona. Physical Geography, 13(2), pp.160-179.

Tayyebi, A., Shafizadeh-Moghadam, H., and Tayyebi, A., H., 2018, Analyzing long-term spatio-temporal patterns of land surface temperature in response to rapid urbanization in the mega-city of Tehran, Land Use Policy, 71, pp. 459-469.

Yang, X., Hou, Y., \& Chen, B., 2011. Observed surface warming induced by urbanization in east China. Journal of Geophysical Research: Atmospheres, 116(D14).

Zhou, L., Dickinson, R. E., Tian, Y., Fang, J., Li, Q., Kaufmann, R. K., ... \& Myneni, R. B., 2004. Evidence for a significant urbanization effect on climate in China. Proceedings of the National Academy of Sciences of the United States of America, 101(26), pp. 9540-9544. 